\title{
The association between BMI and 90-day mortality in patients with and without diabetes seeking care at the emergency department
}

\author{
Per Wändella, Axel C. Carlsson ${ }^{\mathrm{a}, \mathrm{b}}$, Anders Larsson'c, Olle Melander ${ }^{\mathrm{d}, \mathrm{e}}$, Torgny Wessman ${ }^{\mathrm{d}, \mathrm{e}}$, Johan Ärnlöv ${ }^{\mathrm{a}, \mathrm{f}}$ and \\ Toralph Ruge ${ }^{\mathrm{d}, e}$
}

\begin{abstract}
aDepartment of Neurobiology, Care Sciences and Society, Karolinska Institutet, Huddinge, Sweden; ${ }^{b}$ Academic Primary Health Care Centre, Stockholm Region, Stockholm, Sweden; 'Department of Medical Sciences, Uppsala University, Uppsala, Sweden; ${ }^{\mathrm{d} D e p a r t m e n t}$ of Emergency and Internal Medicine, Skånes University Hospital, Malmö, Sweden; 'Department of Clinical Sciences Malmö, Lund University \& Department of Internal Medicine, Skåne University Hospital, Malmö, Sweden; fSchool of Health and Social Studies, Dalarna University, Falun, Sweden
\end{abstract}

\begin{abstract}
Background: The impact of body mass index (BMI) on mortality varies with age and disease states. The aim of this research study was to analyse the associations between BMI categories and short- and long-term mortality in patients with or without diabetes seeking care at the emergency department (ED) with acute dyspnoea.

Population and methods: Patients aged $\geq 18$ years at ED during daytime on weekdays from March 2013 to July 2018 were included. Participants were triaged according to the Medical Emergency Triage and Treatment System-Adult score (METTS-A), and blood samples were collected. Totally, 1,710 patients were enrolled, with missing values in 113, leaving 1,597 patients, 291 with diabetes and 1,306 without diabetes. The association between BMI and short-term (90-day) and long-term (mean follow-up time 2.1 years) mortality was estimated by Cox regression with normal BMI (18.5-24.9) as referent category, with adjustment for age, sex, METTS-A scoring, glomerular filtration rate, smoking habits and cardiovascular comorbidity in a fully adjusted model. The Bonferroni correction was also used.

Results: Regarding long-term mortality, patients with diabetes and BMI category $\geq 30 \mathrm{~kg} / \mathrm{m}^{2}$ had a fully adjusted Hazard Ratio (HR) of 0.40 (95\% confidence interval [CI]: 0.23-0.69), significant after the Bonferroni correction. Amongst patients without diabetes, those with underweight had an increased risk but only of borderline significance, whilst risks in those with overweight or obesity did not differ from reference.

Regarding short-term mortality, risks did not differ from reference amongst patients with or without diabetes.

Conclusions: We found divergent long-term mortality risks in patients with and without diabetes, with lower risk in obese patients (BMI $\geq 30 \mathrm{~kg} / \mathrm{m}^{2}$ ) with diabetes, but no increased risk for patients without diabetes and overweight (BMI: $25-29.9 \mathrm{~kg} / \mathrm{m}^{2}$ ) and obesity.
\end{abstract}

\section{ARTICLE HISTORY}

Received 3 February 2021

Revised 24 August 2021

Accepted 24 August 2021

Published 16 September 2021

\section{KEYWORDS}

Diabetes; BMl; mortality; triage level; emergency department

\section{Introduction}

Globally, body mass index (BMI) has increased during the last few decades (1), with an increasing rate of overweight and obesity, although a plateau phase seems to be reached in many high-income countries (2). Obesity has been proposed as the main upstream driver of cardiometabolic risk factors and associated outcomes (3), such as hypertension, diabetes and myocardial infarction (MI) (4). Moreover, obesity is regarded as one of the leading risk factors for mortality in the world (5). Despite that overweight and obesity are associated with an increased risk of mortality (6), cardiovascular mortality, especially coronary heart disease (CHD), has decreased in Western countries (7), including in Sweden (8), during the last few decades.

The association between BMI and mortality has been explored in many articles. A J- or U-shaped association between BMI and both all-cause and cardiovascular mortality has been reported $(9$, 10). In a study of the risk of being among the lowest $5 \%$ in different anthropometrical measures, both BMI and percent body fat showed an increased mortality risk, whilst all measures showed an excess mortality risk in the highest quartile (11).

A paradoxical risk association has been observed between BMI and mortality, particularly for patients with diabetes, with a higher mortality risk in the BMI range $18.5-24.9 \mathrm{~kg} / \mathrm{m}^{2}(12)$. In a 
recent review, the lowest mortality risk was found for men in the $\mathrm{BMI}$ range $31-35 \mathrm{~kg} / \mathrm{m}^{2}$, and for women in the $\mathrm{BMI}$ range 28-31 kg/m² (13). However, the BMI-mortality paradox in diabetes is still controversial, with some results in agreement (14), and others questioning it $(15,16)$, and the impact of obesity on health can be very different according to age, gender, patient characteristics and the presence of comorbidities, as well as the state of acute or non-acute illness (17). Thus, the role of BMI in patient outcome, whether in long term or short term, is still not clear.

The aim of this study was to determine the effect of BMI on short- and long-term mortality rates in elderly acute ill patients, with or without diabetes, admitted to the emergency department (ED). As a model, we chose a cohort of patients admitted to the ED because of acute dyspnoea, the 'Acute Dyspnea Study' (ADYS) (18), known to include severely ill patients with a high level of comorbidity.

\section{Methods}

\section{Population and methods}

Patients with acute dyspnoea admitted to the ED of SUS Malmö were included in the 'Acute Dyspnea Study' (ADYS) between March 2013 and January 2019. Patients $\geq 18$ years who presented to the ED during daytime, 6:45 AM to 4:30 PM working days with acute dyspnoea as their main complaint, were asked for consent to take part in the study by a research nurse. Critically ill patients who directly were transferred from the resuscitation room to an intensive care unit (ICU) were excluded, as were patients with lower degrees of consciousness as these patients were not able to give consent nor able to partake in answering the questionnaire. Vital parameters were registered as were medical triage priority level according to the validated Medical Emergency Triage and Treatment System (METTS). A total of 1,710 patients were enrolled, in which 113 of these were excluded because of missing values, leaving 1,597 patients for further analyses. Body mass index data were present amongst 1,553 patients, and the 44 missing values were imputed for further analyses (see below). Of the included 1,597 patients, 291 patients had diabetes and 1,306 were without diabetes. Patients with diabetes in this study included both patients with type-1 and type-2 diabetes, and patients were only defined as diabetic if they had been previously diagnosed with diabetes in the electronic patient record.

After inclusion, all patients were interviewed by a research nurse about their health, medication, symptoms and social situation according to a standardised and approved questionnaire. Patients were questioned regarding smoking habits and categorised as non-smokers, former smokers (cessation 1 month ago or longer) or active smokers (regularly smoking the past month or longer), disease history associated with dyspnoea (i.e. congestive heart failure, chronic obstructive pulmonary disease (COPD), asthma, coronary artery disease, atrial fibrillation, restrictivelung disease, cancer, thromboembolic disease or rheumatic disease) and current medications.
Information on weight and height was taken from the medical records if this was recently documented; otherwise, this information was collected at the ED by the research nurse. The research nurses reviewed the patient's medical records in order to confirm the details with the support of senior physicians whenever uncertainties occurred. Originally METTS-A uses five clinical priority levels with increasing clinical priority: blue (lowest clinical priority - not life-threatening), green, yellow, orange and red (highest clinical priority - life-threatening). The lowest clinical priority level, blue, was not used in the clinical triage of the patients included here because of the local triage routines, with the lowest clinical triage priority here being green.

Bodymassindexwas categorised into $<18.5 \mathrm{~kg} / \mathrm{m}^{2}$ (underweight), $18.5-24.9 \mathrm{~kg} / \mathrm{m}^{2}$ (normal weight), $25-29.9 \mathrm{~kg} / \mathrm{m}^{2}$ (overweight) or $\geq 30 \mathrm{~kg} / \mathrm{m}^{2}$ (obesity) (19). High sensitivity C-reactive protein (CRP) was analysed using a particle-enhanced turbidimetric assay, and the creatinine level was analysed using an Integrated Database Management System (IDMS) calibrated enzymatic assay (20). Lactate and glucose were analysed with routine methods. These methods are accredited by Swedac and are included in the Swedish external quality assurance programme for CRP and creatinine, respectively, and are routinely used. Within an hour of presentation at ED, blood was sampled, serum and plasma were separated and subsequently stored at $-80^{\circ} \mathrm{C}$ for future analysis. The assays were performed blinded without knowledge of clinical data. The Chronic Kidney Disease Epidemiology Collaboration (CKD-EPI) equation was used to estimate the glomerular filtrate rate (GFR).

\section{Ethical considerations}

This study obtained ethical approval from 'Regionala Etikprövningsnämnden EPN', Lund, Sweden. Dnr 2014/82. All included patients provided their written informed consent to take part in the study.

\section{Statistics}

Baseline values expressed as numbers, with percentages, or mean values with standard deviation (SD), and Chi-square tests or Analysis of variance (ANOVA) were used for comparisons. The association between the short-term mortality (90-day mortality) and long-term mortality (after total follow-up time of the study, 2.1 \pm 1.5 years), respectively, and BMI categories was analysed by Cox proportional hazard model in univariate analyses and in models adjusted for age, sex (Model A), and the clinical triage scoring system (Model B), and cardiovascular co-morbidity (established coronary disease, heart failure and hypertension), smoking habits and GFR (Model C). We categorised the patients into those with or without diabetes, and performed interaction analyses. Individuals with normal BMI (18.5-24.9) was used as the referent category. We imputed values for BMl (missing in 44 patients), for the completeness of data for further analyses. We also performed a sensitivity analysis for patients with diabetes merging BMI levels $25-29.9$ and $\geq 30 \mathrm{~kg} / \mathrm{m}^{2}$ using Models A and C, as the Hazard Ratio (HR) showed similar values for both these categories. 
The follow-up time stretched from the time of presentation at the ED to death within or the end of follow-up (90 days postpresentation and total mortality $2.1 \pm 1.5$ years). A $P$-value of $<0.05$ was considered to be statistically significant, and we also performed a Bonferroni correction (with 0.05 divided by 9 for statistical significance of outcomes using each group of models per patient group as a unit). The dataset was handled, and Cox proportional hazard models were all computed with IBM SPSS statistics 25.0 software (SPSS Inc., Chicago, IL).

\section{Results}

\section{General data}

Baseline data show that patients with diabetes were older, with higher mean BMI, and with higher lactate, glucose and creatinine levels (Table 1). Patients with diabetes also were more often admitted to hospital care, and more often were diagnosed with heart failure, CHD, stroke and hypertension than those without diabetes. Mortality, according to the BMI interval for 90-day mortality, shows the highest risk for diabetes patients in the normal BMI interval, that is, $18.5-24.9 \mathrm{~kg} / \mathrm{m}^{2}$, with $21 \%$, and for patients without diabetes in the underweight interval, that is, $<18.5 \mathrm{~kg} / \mathrm{m}^{2}$ with $22 \%$ (Table 2). There were no deaths reported amongst the two patients with diabetes in the BMl interval $<18.5 \mathrm{~kg} / \mathrm{m}^{2}$.

Table 1. Baseline characteristics of patients with acute dyspnoea, with and without diabetes seeking care at a hospital emergency department.

\begin{tabular}{|c|c|c|}
\hline Variable & $\begin{array}{l}\text { Diabetes } \\
(n=291)\end{array}$ & $\begin{array}{l}\text { No diabetes } \\
(n=1,306)\end{array}$ \\
\hline Female & $44 \% * * *$ & $58 \%$ \\
\hline Age at survey (years) & $74(14)^{* * *}$ & $69(19)$ \\
\hline Body mass index $\left(\mathrm{kg} / \mathrm{m}^{2}\right)$ & $30(7)^{* * *}$ & $26(6)$ \\
\hline Systolic blood pressure (mmHg) & $148(27)$ & $146(29)$ \\
\hline Diastolic blood pressure $(\mathrm{mmHg})$ & $80(18)$ & $82(16)$ \\
\hline Respiratory rate (frequency) & $25(7)$ & $24(7)$ \\
\hline C-reactive protein (CRP, mg/L) & $30(53)$ & $35(64)$ \\
\hline Lactate $(\mathrm{mmol} / \mathrm{L})$ & $2.1(1.2)^{* * *}$ & $1.7(1.04)$ \\
\hline Glucose level (mmol/L) & $11.0(5.9)^{* * * *}$ & $6.9(2.4)$ \\
\hline Creatinine $(\mu \mathrm{mol} / \mathrm{L})$ & $125.3(100.6)^{* * *}$ & $93.0(69.4)$ \\
\hline \multicolumn{3}{|l|}{ METTS-A triage } \\
\hline Red - most acute (\%) & 16 & 12 \\
\hline Orange (\%) & 32 & 31 \\
\hline Yellow (\%) & 49 & 50 \\
\hline Green - least acute (\%) & 4 & 7 \\
\hline Admitted to hospital care (\%) & $69^{* * *}$ & 46 \\
\hline Cancer $(\%)$ & $24^{*}$ & 18 \\
\hline Chronic obstructive pulmonary disease (\%) & 29 & 30 \\
\hline Chronic heart failure (\%) & $53^{* * *}$ & 29 \\
\hline Coronary artery disease (\%) & $50^{* * *}$ & 24 \\
\hline Stroke $(\%)$ & $17^{* * *}$ & 9 \\
\hline Hypertension (\%) & $63^{* * *}$ & 37 \\
\hline 90-day mortality (\%) & 14 & 12 \\
\hline
\end{tabular}

Missing data points were less than $4 \%$ for all included characteristics, except for diastolic blood pressure and lactate where around $8 \%$ of data points were missing. Means and standard deviations, or percentages, ${ }^{*} P<0.05,{ }^{* * *} P<0.001$; for differences between individuals with or without diabetes.

\section{0-day mortality}

There was no significant interaction for the mortality between patients with and without diabetes $(P<0.07)$. Patients with diabetes and in the BMI intervals $25-29.9$ and $\geq 30 \mathrm{~kg} / \mathrm{m}^{2}$ showed no statistically decreased mortality risk (Table 3). Patients without diabetes had the highest risk in the BMI interval $<18.5 \mathrm{~kg} / \mathrm{m}^{2}$; however, it is not statistically significant after the Bonferroni correction (Bonferroni-adjusted $P$-level $<0.006$ ).

\section{Long-term mortality}

There was a significant interaction between patients with and without diabetes as regards long-term mortality $(P<0.0001)$. In patients with diabetes, a significantly lower mortality risk was found in the BMI interval $\geq 30 \mathrm{~kg} / \mathrm{m}^{2}$ in all three models (Table 4), also statistically significant after the Bonferroni correction (Bonferroni adjusted $P$-level $<0.001)$. In patients without diabetes and BMI $<18.5 \mathrm{~kg} / \mathrm{m}^{2}$, the results showed a statistically borderline higher risk after the Bonferroni correction (Bonferroni-adjusted $P$-level $=0.006$ ).

\section{Discussion}

We found different patterns between individuals with and without diabetes as regards mortality in different BMI intervals. Regarding long-term mortality, patients with diabetes and BMI $\geq 30 \mathrm{~kg} / \mathrm{m}^{2}$ showed a significantly lower risk than the reference, whilst patients without diabetes and underweight showed higher risk but only of borderline significance.

As regards diabetes patients with obesity, that is, BMI $\geq 30$ $\mathrm{kg} / \mathrm{m}^{2}$, the statistically significant lower risk are in line with the BMI-mortality paradox, that is, with lower mortality risks at higher BMI intervals, in contrast with results from large population studies showing an excess risk in the overweight and obesity interval $(9,21)$. In contrast, we could not find any statistically significant association between underweight and an increased mortality, but there were only two patients within this BMI interval.

Table 2. Data on a 90-day mortality by BMI categories in patients seeking care for dyspnoea at the emergency department with $(n=291)$ or without $(n=1,306)$ diabetes.

\begin{tabular}{lll}
\hline BMI categories & $\begin{array}{l}\text { Patients with diabetes } \\
\text { Number of mortality } \\
\text { events or numbers at } \\
\text { risk (\%) }\end{array}$ & $\begin{array}{l}\text { Patients without } \\
\text { diabetes } \\
\text { Number of mortality } \\
\text { events or numbers at } \\
\text { risk (\%) }\end{array}$ \\
\hline 90-day mortality: & & \\
BMI < 18.5 kg/m² & $0 / 2(0)$ & $18 / 83(22)$ \\
BMI $18.5-24.9 \mathrm{~kg} / \mathrm{m}^{2}$ & $16 / 76(21)$ & $59 / 580(10)$ \\
BMI $25-29.9 \mathrm{~kg} / \mathrm{m}^{2}$ & $10 / 89(11)$ & $41 / 328(13)$ \\
BMI $\geq 30 \mathrm{~kg} / \mathrm{m}^{2}$ & $11 / 114(10)$ & $27 / 281(10)$ \\
Total mortality: & & $32 / 83(39)$ \\
BMI $<18.5 \mathrm{~kg} / \mathrm{m}^{2}$ & $1 / 2(50)$ & $136 / 580(23)$ \\
BMI $18.5-24.9 \mathrm{~kg} / \mathrm{m}^{2}$ & $37 / 76(49)$ & $66 / 328(20)$ \\
BMI $25-29.9 \mathrm{~kg} / \mathrm{m}^{2}$ & $31 / 89(35)$ & $52 / 281(18)$ \\
BMI $\geq 30 \mathrm{~kg} / \mathrm{m}^{2}$ & $25 / 114(22)$ &
\end{tabular}

BMI: body mass index. 
Table 3. The associated risk between non-normal BMI and 90-day mortality in patients with or without diabetes seeking care at a hospital emergency department.

\begin{tabular}{|c|c|c|c|c|c|c|}
\hline \multirow[t]{2}{*}{ BMI categories } & \multicolumn{3}{|c|}{ Patients with diabetes (HR, 95\% Cl) } & \multicolumn{3}{|c|}{ Patients without diabetes (HR, 95\% Cl) } \\
\hline & Model A & Model B & Model C & Model A & Model B & Model C \\
\hline $\mathrm{BMI}<18.5$ & - & - & - & $\begin{array}{l}2.11 \\
(1.24-3.60)\end{array}$ & $\begin{array}{l}2.11 \\
(1.24-3.60)\end{array}$ & $\begin{array}{l}2.33 \\
(1.75-3.11)\end{array}$ \\
\hline BMI 18.5-24.9 & Referent & Referent & Referent & Referent & Referent & Referent \\
\hline BMI 25-29.9 & $\begin{array}{l}0.54 \\
(0.24-1.20)\end{array}$ & $\begin{array}{l}0.68 \\
(0.29-1.60)\end{array}$ & $\begin{array}{l}0.54 \\
(0.21-1.38)\end{array}$ & $\begin{array}{l}1.23 \\
(0.83-1.84)\end{array}$ & $\begin{array}{l}1.23 \\
(0.82-1.84)\end{array}$ & $\begin{array}{l}1.22 \\
(0.87-1.72)\end{array}$ \\
\hline $\mathrm{BMI} \geq 30$ & $\begin{array}{l}0.46 \\
(0.21-1.02)\end{array}$ & $\begin{array}{l}0.50 \\
(0.22-1.11)\end{array}$ & $\begin{array}{l}0.50 \\
(0.22-1.13)\end{array}$ & $\begin{array}{l}1.20 \\
(0.75-1.88)\end{array}$ & $\begin{array}{l}1.23 \\
(0.77-1.95)\end{array}$ & $\begin{array}{l}1.24 \\
(0.77-1.98)\end{array}$ \\
\hline
\end{tabular}

BMI: body mass index; Cl: confidence interval; Hazard Ratio (HR): .

Analyses include imputed data for missing values for BMI.

Model A includes age and sex; Model B includes Model A and METTS-A triage; Model C includes Model B and cardiovascular comorbidity (established coronary disease, heart failure and hypertension), smoking and GFR. With the Bonferroni correction, the results of patients without diabetes were not statistically significant (corrected P-level $<0.006$ was not satisfied).

Table 4. The associated risk between non-normal BMI and mortality after the total follow-up time in the study (after 2.1 years, \pm 1.5 years) in patients with or without diabetes seeking care at a hospital emergency department.

\begin{tabular}{|c|c|c|c|c|c|c|}
\hline \multirow[t]{2}{*}{ BMI categories } & \multicolumn{3}{|c|}{ Patients with diabetes ( $\mathrm{HR}, 95 \% \mathrm{Cl})$} & \multicolumn{3}{|c|}{ Patients without diabetes (HR, 95\% Cl) } \\
\hline & Model A & Model B & Model C & Model A & Model B & Model C \\
\hline $\mathrm{BMI}<18.5$ & $\begin{array}{l}0.67 \\
(0.09-4.97)\end{array}$ & $\begin{array}{l}0.95 \\
(0.12-7.25)\end{array}$ & $\begin{array}{l}1.32 \\
(0.17-10.38)\end{array}$ & $\begin{array}{l}1.67 \\
(1.13-2.47)\end{array}$ & $\begin{array}{l}1.64 \\
(1.34-2.00)\end{array}$ & $\begin{array}{l}1.76 \\
(1.43-2.17)\end{array}$ \\
\hline BMI 18.5-24.9 & Referent & Referent & Referent & Referent & Referent & Referent \\
\hline BMI 25-29.9 & $\begin{array}{l}0.66 \\
(0.41-1.08)\end{array}$ & $\begin{array}{l}0.83 \\
(0.49-1.39)\end{array}$ & $\begin{array}{l}0.82 \\
(0.47-1.42)\end{array}$ & $\begin{array}{l}0.86 \\
(0.64-1.15)\end{array}$ & $\begin{array}{l}0.88 \\
(0.65-1.18)\end{array}$ & $\begin{array}{l}0.82 \\
(0.60-1.10)\end{array}$ \\
\hline $\mathrm{BMI} \geq 30$ & $\begin{array}{l}0.41 \\
(0.24-0.69)^{*}\end{array}$ & $\begin{array}{l}0.44 \\
(0.26-0.75)^{*}\end{array}$ & $\begin{array}{l}0.40 \\
(0.23-0.69)^{*}\end{array}$ & $\begin{array}{l}0.95 \\
(0.68-1.31)\end{array}$ & $\begin{array}{l}0.99 \\
(0.72-1.37)\end{array}$ & $\begin{array}{l}0.94 \\
(0.67-1.31)\end{array}$ \\
\hline
\end{tabular}

BMI: body mass index; Cl: confidence interval; Hazard Ratio (HR): .

Analyses include imputed data for missing values for BMI.

Model A includes age and sex; Model B includes Model A and METTS-A triage; Model C includes Model B and cardiovascular comorbidity (established coronary disease, heart failure and hypertension), smoking and GFR. With the Bonferroni correction, the results in the diabetes group were statistically significant (corrected $P$-level $<0.006$ was satisfied); however, in the non-diabetes group the values were borderline significant (corrected $P$-level $=0.006)$.

${ }^{*} P<0.05$ with the Bonferroni correction.

One of the German studies of patients with type-2 diabetes revealed a U-shaped curve, with the lowest mortality rates for individuals with BMI at around $31 \mathrm{~kg} / \mathrm{m}^{2}$ (22). Another study on patients with type 2 diabetes revealed a lower mortality rate among individuals with overweight and obesity class I (BMI $30-34.9 \mathrm{~kg} / \mathrm{m}^{2}$ ) compared to individuals with normal BMI (23). A systematic review and meta-analysis confirmed these findings, with a higher mortality in underweight, that is, $<18.5 \mathrm{~kg} / \mathrm{m}^{2}$, and a lower mortality in overweight and mild obesity compared with normal BMI (24).

For patients without diabetes, we found no statistically significant results, but a borderline significance for underweight after the Bonferroni correction. Overweight and obesity were not associated with an increased mortality rate. Large studies have shown a $\mathrm{U}$ - or J-shaped curve, with the lowest BMI risk in individuals in the normal BMI interval (21). The research findings with a similar mortality in patients with overweight and obesity as in patients with normal weight thus in some respects could be seen as a marker of the obesity paradox. Underweight has been associated with an increased mortality in earlier, large population studies $(9-11,25)$. Furthermore, the association between underweight and increased mortality seems to be more pronounced in individuals with respiratory diseases (21). Actually, patients in this study actually had dyspnoea.

The obesity paradox has certainly been questioned. One of the reviews on the obesity paradox concluded on studies supporting this hypothesis: 'these studies have numerous limitations due to their mainly retrospective nature and to numerous confounding factors, such as associated pathologies, antidiabetic treatments, smoking habit, lack of data about distribution of body fat or weight history' (16), and another review on the same topic shows 'conflicting evidence for the role of overweight and obesity in all-cause mortality may largely be a result of differences in study populations, epidemiological methods, and statistical analysis' (15).

The reason for findings related to the obesity paradox has been discussed. Amongst patients with congestive heart failure, one of the studies found that increasing BMI was associated with lower mortality (26), especially for in-hospital mortality (27). Another study found the obesity paradox to be present, 
however, not in patients with diabetes (28), contradictory to the study findings. Yet, another study confirmed not only the association between higher BMI and lower mortality in patients with heart failure but also an association between being underweight and higher mortality (29). However, this study also concluded that the influence is complex, and that the effect of $\mathrm{BMI}$ was depending on the ejection fraction and the presence or absence of COPD (29). In contrast, for patients with COPD, obesity was associated only with mortality from respiratory causes and only in the BMl interval $>40 \mathrm{~kg} / \mathrm{m}^{2}$ (30).

Excess mortality in low BMI could be explained by cancer mortality or smoking habits, but adjusting for this or by categorising into causes of mortality has shown that the BMImortality paradox still exists (12). Smoking has been shown to increase the mortality risk in the lower BMI interval (9). For patients with COPD, underweight is shown to be associated with increased mortality (30).

The patients in this study represent a special group, that is, patients seeking care at a hospital ED with symptoms of dyspnoea, and within this specific group it might be more dangerous being to lean. An earlier study in patients with acute MI found that excess weight at the time of MI was associated with a lower mortality, whilst in the long term it was associated with recurrent re-infarction and cardiac death (31). A review also confirmed the obesity paradox in $\mathrm{Ml}$, but also finding that this was true for long-term mortality (32), in contrast to other studies.

Thus, in general, there are contradictory findings related to the obesity paradox. An increased risk with underweight is regularly shown $(9,21)$; however, the relation between higher BMI intervals, that is, overweight and obesity, and mortality differs between studies, thus seemingly supporting the critical views in some reviews $(15,16)$. More studies on the possible effects of the obesity paradox in specific groups are warranted.

There are some limitations with this study. This is an observational study, and we had data only at baseline and not at follow-up. The sample was rather small with a small number of deaths, with a low statistical power. However, the sample represents a specific group in a specific setting, that is, patients with dyspnoea seeking care at the ED. We have no data on individual BMI trends. Furthermore, we imputed BMI values, which could have distorted the results, especially in the diabetes group, and this is why the results should be interpreted with some caution. Furthermore, the number of underweight patients was rather small, especially in the diabetes group with only two patients, and the association with mortality was not statistically significant after the Bonferroni correction, even if the mortality rate was highest within this group. The main aim was originally to study the association between BMI and shortterm mortality; however, we also added the total registered mortality. Furthermore, the research study was not designed to analyse the work or effect of emergency care on patient outcomes, as there are too many unknown variables for analysis. We cannot generalise to other patient- age- and ethnic groups. Strengths of the study include the longitudinal study design and the use of real-world clinical data from a well-characterised cohort consisting of acute ill patients.

\section{Conclusions}

We found for diabetes patients with overweight or obesity a lower overall mortality, in line with the obesity paradox, whilst those without diabetes no increased mortality was found for obesity, and the higher risk for underweight showed borderline significance after the Bonferroni correction. Taken together, our data suggest that obesity in this specific patient group seems to have a protective effect on patients with diabetes, and with no increased mortality risk for patients without diabetes compared with those with normal weight.

\section{Disclosure statement}

The authors report no conflicts of interest.

\section{Funding}

No funding was received for this research work.

\section{Notes on contributors}

Per Wändell, MD and PhD, is a specialist in family medicine and senior professor in family medicine at Karolinska Institutet, Department of Neurobiology, Care Sciences and Society, Division of Family Medicine and Primary Care.

Axel C. Carlsson, PhD, is a pharmacist and associate professor in family medicine at Karolinska Institutet, Department of Neurobiology, Care Sciences and Society, Division of Family Medicine and Primary Care.

Anders Larsson, MD'and $\mathrm{PhD}$, is a senior consultant in clinical chemistry and professor in clinical chemistry at Uppsala University, Department of Medical Sciences, Clinical Chemistry.

Olle Melander, MD and PhD, is a professor of Internal Medicine at Lund University and a consultant at the Department of Internal Medicine, Skåne University Hospital.

Torgny Wessman, Torgny Wessman, MD and PhD student, is a specialist in general medicine and emergency medicine at Lund University, Faculty of Medicine, Department of Clinical Sciences Malmö. He is also a senior consultant at the Emergency Department, Skåne University Hospital, Malmö.

Johan Ärnlöv, MD and PhD, is a specialist in family medicine and a professor in family medicine at Karolinska Institutet, Department of Neurobiology, Care Sciences and Society, Division of Family Medicine and Primary Care.

Toralph Ruge, Toralph Ruge, MD and PhD, is a specialist in family medicine and emergency medicine and an associate professor in Emergency medicine at Lunds University.

\section{ORCID}

Per Wändell (D) http://orcid.org/0000-0001-5169-2965

Axel C. Carlsson (D) http://orcid.org/0000-0001-6113-0472 
Anders Larsson (10 http://orcid.org/0000-0003-3161-0402 Olle Melander (D) https://orcid.org/0000-0002-2581-484X Torgny Wessman (D) http://orcid.org/0000-0002-7314-2240 Johan Ärnlöv (D) http://orcid.org/0000-0002-6933-4637 Toralph Ruge (D) http://orcid.org/0000-0002-1170-5183

\section{References}

1. Finucane MM, Stevens GA, Cowan MJ, Danaei G, Lin JK, Paciorek CJ, et al. National, regional, and global trends in body-mass index since 1980: systematic analysis of health examination surveys and epidemiological studies with 960 country-years and 9.1 million participants. Lancet. 2011;377:557-67. doi: 10.1016/S0140-6736(10)62037-5

2. Collaboration NCDRF. Worldwide trends in body-mass index, underweight, overweight, and obesity from 1975 to 2016: a pooled analysis of 2416 population-based measurement studies in 128.9 million children, adolescents, and adults. Lancet. 2017;390:2627-42.

3. Haslam DW, James WP. Obesity. Lancet. 2005;366:1197-209. doi: 10.1016/S0140-6736(05)67483-1

4. Zhu J, Su X, Li G, Chen J, Tang B, Yang Y. The incidence of acute myocardial infarction in relation to overweight and obesity: a meta-analysis. Arch Med Sci. 2014;10:855-62. doi: 10.5114/aoms.2014.46206

5. Narayan KM, Ali MK, Koplan JP. Global noncommunicable diseases where worlds meet. N Engl J Med. 2010;363:1196-8. doi: 10.1056/ NEJMp1002024

6. Flegal KM, Kit BK, Orpana H, Graubard BI. Association of all-cause mortality with overweight and obesity using standard body mass index categories: a systematic review and meta-analysis. JAMA. 2013;309:71-82. doi: 10.1001/jama.2012.113905

7. Kesteloot H, Sans S, Kromhout D. Dynamics of cardiovascular and allcause mortality in Western and Eastern Europe between 1970 and 2000. Eur Heart J. 2006;27:107-13. doi: 10.1093/eurheartj/ehi511

8. Bjorck L, Rosengren A, Bennett K, Lappas G, Capewell S. Modelling the decreasing coronary heart disease mortality in Sweden between 1986 and 2002. Eur Heart J. 2009;30:1046-56. doi: 10.1093/eurheartj/ehn554

9. Berrington de Gonzalez A, Hartge P, Cerhan JR, Flint AJ, Hannan L, Maclnnis RJ, et al. Body-mass index and mortality among 1.46 million white adults. N Engl J Med. 2010;363:2211-9. doi: 10.1056/NEJMoa1000367

10. Song $X$, Jousilahti $P$, Stehouwer $C D$, Soderberg $S$, Onat $A$, Laatikainen $T$, et al. Cardiovascular and all-cause mortality in relation to various anthropometric measures of obesity in Europeans. Nutr Metab Cardiovasc Dis. 2015;25:295-304. doi: 10.1016/j.numecd.2014.09.004

11. Wierup I, Carlsson AC, Wandell P, Riserus U, Arnlov J, Borne Y. Low anthropometric measures and mortality - results from the Malmo Diet and Cancer Study. Ann Med. 2015;47:325-31. doi: 10.3109/07853890.2015.1042029

12. Kokkinos P, Myers J, Faselis C, Doumas M, Kheirbek R, Nylen E. BMI-mortality paradox and fitness in African American and Caucasian men with type 2 diabetes. Diabetes Care. 2012;35:1021-7. doi: 10.2337/dc11-2407

13. Zaccardi F, Dhalwani NN, Papamargaritis D, Webb DR, Murphy GJ, Davies MJ, et al. Nonlinear association of BMI with all-cause and cardiovascular mortality in type 2 diabetes mellitus: a systematic review and meta-analysis of 414,587 participants in prospective studies. Diabetologia. 2017;60:240-8. doi: 10.1007/s00125-016-4162-6

14. Han SJ, Boyko EJ. The evidence for an obesity paradox in type 2 diabetes mellitus. Diabetes Metab J. 2018;42:179-87. doi: 10.4093/dmj.2018.0055

15. Tobias DK, Manson JE. The obesity paradox in type 2 diabetes and mortality. Am J Lifestyle Med. 2018;12:244-51. doi:10.1177/1559827616650415

16. Gravina G, Ferrari F, Nebbiai G. The obesity paradox and diabetes. Eat Weight Disord. 2021;26:1057-1068. doi: 10.1007/s40519-020-01015-1
17. Yoo HJ. Body mass index and mortality. J Obes Metab Syndr. 2017;26:3-9. doi: 10.7570/jomes.2017.26.1.3

18. Carlsson AC, Wessman T, Larsson A, Leijonberg G, Tofik R, Arnlov J, et al. Endostatin predicts mortality in patients with acute dyspnea - a cohort study of patients seeking care in emergency departments. Clin Biochem. 2020;75:35-9. doi: 10.1016/j.clinbiochem.2019.10.004

19. Gallagher D, Heymsfield SB, Heo M, Jebb SA, Murgatroyd PR, Sakamoto $Y$. Healthy percentage body fat ranges: an approach for developing guidelines based on body mass index. Am J Clin Nutr. 2000;72:694-701. doi: 10.1093/ajen/72.3.694

20. Wiklund K, Gransbo K, Lund N, Peyman M, Tegner L, Toni-Bengtsson M, et al. Inflammatory biomarkers predicting prognosis in patients with acute dyspnea. Am J Emerg Med. 2016;34:370-4. doi: 10.1016/j.ajem.2015.10.052

21. Global BMI Mortality Collaboration, Di Angelantonio E, Bhupathiraju Sh $\mathrm{N}$, Wormser D, Gao P, Kaptoge S, et al. Body-mass index and all-cause mortality: individual-participant-data meta-analysis of 239 prospective studies in four continents. Lancet. 2016;388:776-86. doi: 10.1016/ S0140-6736(16)30175-1

22. Kowall B, Stang A, Erbel R, Moebus S, Petersmann A, Steveling A, et al. Is the obesity paradox in type 2 diabetes due to artefacts of biases? An analysis of pooled cohort data from the Heinz Nixdorf Recall Study and the Study of Health in Pomerania. Diabetes Metab Syndr Obes. 2020;13:1989-2000. doi: 10.2147/DMSO.S242553

23. Pagidipati NJ, Zheng Y, Green JB, McGuire DK, Mentz RJ, Shah S, et al. Association of obesity with cardiovascular outcomes in patients with type 2 diabetes and cardiovascular disease: insights from TECOS. Am Heart J. 2020;219:47-57. doi: 10.1016/j.ahj.2019.09.016

24. Chang HW, Li YH, Hsieh CH, Liu PY, Lin GM. Association of body mass index with all-cause mortality in patients with diabetes: a systemic review and meta-analysis. Cardiovasc Diagn Ther. 2016;6:109-19. doi: 10.21037/cdt.2015.12.06

25. Wandell PE, Carlsson AC, Theobald H. The association between BMI value and long-term mortality. Int J Obes (Lond). 2009;33:577-82. doi: 10.1038/ijo.2009.36

26. Curtis JP, Selter JG, Wang Y, Rathore SS, Jovin IS, Jadbabaie F, et al. The obesity paradox: body mass index and outcomes in patients with heart failure. Arch Intern Med. 2005;165:55-61. doi: 10.1001/archinte.165.1.55

27. Fonarow GC, Srikanthan P, Costanzo MR, Cintron GB, Lopatin M, Committee ASA, et al. An obesity paradox in acute heart failure: analysis of body mass index and inhospital mortality for 108,927 patients in the Acute Decompensated Heart Failure National Registry. Am Heart J. 2007;153:74-81. doi: 10.1016/j.ahj.2006.09.007

28. Zamora E, Lupon J, Enjuanes C, Pascual-Figal D, de Antonio M, Domingo $M$, et al. No benefit from the obesity paradox for diabetic patients with heart failure. Eur J Heart Fail. 2016;18:851-8. doi: 10.1002/ejhf.576

29. Gustafsson F, Kragelund CB, Torp-Pedersen C, Seibaek M, Burchardt H, Akkan $D$, et al. Effect of obesity and being overweight on long-term mortality in congestive heart failure: influence of left ventricular systolic function. Eur Heart J. 2005;26:58-64. doi: 10.1093/eurheartj/ehi022

30. Jordan JG, Jr., Mann JR. Obesity and mortality in persons with obstructive lung disease using data from the NHANES III. South Med J. 2010;103:323-30. doi: 10.1097/SMJ.0b013e3181d394b4

31. Nigam A, Wright RS, Allison TG, Williams BA, Kopecky SL, Reeder GS, et al. Excess weight at time of presentation of myocardial infarction is associated with lower initial mortality risks but higher long-term risks including recurrent re-infarction and cardiac death. Int J Cardiol. 2006;110:153-9. doi: 10.1016/j.ijcard.2005.06.040

32. Wang L, Liu W, He X, Chen Y, Lu J, Liu K, et al. Association of overweight and obesity with patient mortality after acute myocardial infarction: a meta-analysis of prospective studies. Int J Obes (Lond). 2016;40:220-8. doi: 10.1038/ijo.2015.176 